\title{
THE DECODING OF A FORMAT : EXAMPLES FROM MUSIC RADIO PRODUCTION IN SWEDEN AND ESTONIA
}

\author{
Michael FORSMAN, Fredrik STIERNSTEDT ${ }^{1}$
}

Radio as technology and cultural form has played an important role in the constructions of national, regional and local political consciousnesses, throughout the world and over the 20th century. Radio has also had an essential position in the (re)creations and (re)presentations of communicative modes and ideals. It has also been partaking in time and space formations as well as identities and structures of everyday life in modernity (for example Durham Peters 1999 ; Scannell 1996 ; Thompson 1995 ; Williams 1975).

Correspondingly, the field of radio research has been comprehensive and wide-ranging. Although with some bias towards a westernised or Anglo-Saxon perspective focused on national (public service) broadcasting. Within this context radio's role in society has often been understood as consisting of the transporting of particular programs partaking in the creation and mediation of a public sphere. Or it has been seen as a

1 Media \& Communication Studies, School of Media, Arts and Philosophy, Södertörns högskola (University College)

Recherches en communication, $\mathrm{n}^{\circ} 26$ (2006). 
designer and promoter of a senus communis or an imagined community (Andersson, 1992). This focus on radio's role in democracy has led to yet another bias in radio research : the idealisation of local, community-, micro- or public access radio. Highlighting the potentials for media democratisation in non-commercial, non-governmental controlled and non-listener radio (a discourse triggered anew by new technologies for disseminating audio over the Internet [see for example Coyer, 2005]).

These discourses have however somewhat overlooked the fact that radio as a mass medium for long and for many people mainly has functioned as entertainment and play. Previous research also has had a blind eye to radio as soundscape or as a generator of modes, in relation to which a variety of ritualised practices and structures of feelings among audiences, as well as audience ratings and the 'production' of audience, seem to be the core rather than an effect of output. This type of radio stations, based on commercial logics and centred on music formats, with hardly any journalistic or enlightening agenda whatsoever, are mediators between a global (though mainly western in origin) space of popular music and local or national space of transmission and reception.

Such music formats seem to be more and more remnant on the European radio landscapes. The increase of format production arguably amplifies the trans-nationalisation of radio, somewhat counteracting previous notions and ideals of radio as a mainly local or national medium. Much contemporary radio is owned and controlled by transnational media companies and the output is creating more of a transnational sameness than ever before, through the standardised modes of production and global flows of popular music. The very idea of trans-nationalisation seems immanent in the notion of format production as such. For example, according to Danish media researcher Pia Majbritt Jensen (2005) the common sense understanding of formats among producers themselves is an idea of a specific content and mode of programming that is conducted, produced and broadcasted in at least two separate national contexts (Jensen, 2005, p. 4) And this is also how Moran $(1998 ; 2003)$ defines the function of format, as a « cultural technology which governs the flow of program ideas across time and space $»$ (Moran, 1998, p. 23).

However, the production and enacting of these trans-national formulas are made in distinct places, in concrete and tangible surroundings and they are produced (as well as received) in different and differentiating contexts. In the following we will introduce an exploratory 
discussion about how to study these processes from the perspective of the radio producers themselves, situated, at the same time in the very local and utterly specific contexts of production, as well as in the borderless flows of trans-national radio rhythms. We argue for a need for empirical studies of the actual process of why, when and how different formats are adapted, but also of how they change over time due to different national contexts, within different radio stations. Part of our argument is that despite the standardised character of format radio, individual actors and conflicts over decisions made on how to adapt, apply, develop and adjust a format makes a difference.

For this discussion we have turned to Stuart Hall's well-known model of encoding and decoding. Halls view on encoding is grounded in a structuralistic / semiotic (and marxist) mode but also has a more sociological and culturalistic view on media reception as interpretation (decoding) (Hall, 1980). Following the argument made by Norwegian media researcher Espen Ytreberg (1999) that the encoding process can be seen as a form of decoding - of a genre, a format, etc - we argue for the need to study what actually happens in the interpretation of the format in the different contexts of stations in different nations.

In this article our empirical focus is on format as a mode of production in relation to the Swedish music radio station Rix FM and the Estonian Star FM. The two radio stations are (pseudo-individualised) identical products, having the same owner ; the trans-national media company MTG, programming the same kind of music in the AC-format, intermediated by identical jingles, and with disc jockeys talking to the same model listener. Further the two stations have identical graphical profiles, homepages, and logotypes, even though they are operating in, and are operated from, two (presumably) different contexts. Empirically this case has been explored through interviews, participant observations and document analysis, studying different actors, choices made, views stated and perspectives taken.

The article starts with a short review of Stuart Hall's encoding/ decoding-model, where we are recoding it for our purposes, followed by a short presentation of the two stations studied, an introduction to the concept of format and then a more empirical and analytical part follows. The closing discussion will suggest some starting points for constructing a more general model or a method for further study of the questions raised in this text. 


\section{Recoding the encoding-decoding model}

Stuart Hall's article Encoding-decoding is a seminal attempt to discuss the relation between media texts and contexts in production as well as in reception. In Halls model encoding is understood as the production of a «meaningful discourse », seen as a combination of determining factors and a relative autonomy for the creators of meaning, the audience. This process is understood as the interplay between the « frameworks of knowledge », the « relations of production » and the «technical infrastructure » within a negotiation between recipient and text. The decoding of texts is structurally determined, but the determining factors give room for a relative autonomy where there might be different interpretations of the media text (i.e confirming, negotiating, oppositional) (Hall, 1980).

On the encoding side however there is in Hall's model - or at least has been in the interpretations and uses of it in later research an emphasis on the determining factors of economy or technology. One example of a different approach however is the Norwegian media researcher Espen Ytrebergs dissertation. Ytrebergs study and empirical material concerning the negotiations about a reorientation within the Norwegian public service television (NRK) in the mid 90s and primarily focuses on « frameworks of knowledge » and « relations of production ». In this way he shows that also the encoding is the result of a decoding process in the line of planning and production bringing forth a lot of negotiations, compromises and conflicts (Ytreberg, 1999; 2000).

Ytreberg also makes the point that all communicative processes must have some sort of « communicative intentionality $»^{1}$. The agency behind the intentionality within production can be discussed and studied on many different levels, as institutional and structural or as individual, from the board of directors to aspects in the concrete production process (Ibid.). This intentionality is both related to the decoding of what is at stake for the whole company (for example the idea of being a public service company and what that means on different levels) to how to produce in relation to a given slot, audience segment or genre or format. This chain of intentionality can hardly be seen as an unpro-

1 Criticising the, in Ytrebergs perspective, all too un-critical reception of poststructuralist idea of the death of the author within media studies, ruling out and banishing questions of intent within research. 
blematic linear flow. It is rather a, more or less, ambivalent process, marked by conflicts of interest and different interpretations depending on position and agency.

In most commercial radio stations the communicative and mediating intention of reaching and relating to an actual audience seems intersected by a strategic (business oriented) intention of choosing and holding on to a rational production process and a competitive format in relation to the radio market in question, i.e. the whole enterprise is about « delivering ears to advertisers ». The third dimension of the production practices of formatted music radio are the ratings and the actual and future potential for incomes from advertising, this can be described as the evaluative dimension of the process. The key to the ideas structuring format production (programming) is assuredly the making of economic surplus value, which is done through the production of an « audience » as an immaterial commodity possibly to trade on an advertising market (See Bolin 2005b). But, in order to understand the processes of format production, one has to understand what the format facilitates, not what essentially is but what it permits through the negotiations of production. The idea of the format of the station in question production is decoded - through the act of programming - within different production sites of commercial radio (production sites where cultural, aesthetic and other symbolic values might be as remnant as the economic rational of format production).

\section{Rix FM and Star FM : A presentation}

Rix FM was introduced, originally under the name Z Radio, when Swedish radio was de-regulated in 1993. In 1996 it was renamed Radio Rix and later, in 1998, Rix FM. Today it is the largest commercial radio station in Sweden, broadcasting as a network on 38 of the 83 original local concessions given for commercial radio in Sweden. The company behind this networked production feed is the large Swedish media company MTG. The station is programming a MoR (Middle of the Road) or AC-format, playing popular music for adults covering mainly pop, rock and soul from the 1990s until today. Rix FM seeks its audience among listener in there 30's and 40's with an interest in consumption, home decoration, fashion and travelling. The station is situated in the inner part of Stockholm. About 50 people work in the station ; of those, 12 are working with the actual programme feed. The 
station is networked and has an almost national coverage. Listening figures are somewhere about $18 \%$ on a weekly basis (RUAB, www. ruab.se)

Star FM has been operating in Estonia since 1998. It was launched by MTG as part of their vast venture into the Baltic media markets. The Estonian station was for quite a long time operated and managed as a filial to Rix FM. Technology (studio and broadcasting equipment) was shipped from Sweden to Estonia and music programming was, for the first years of the stations history, conducted from Sweden. During this time Star FM was also a part of the Swedish branch of MTG Radio. In the beginning of the $21^{\text {st }}$ century Star FM was incorporated in MTG UK, and the contacts between Swedish Rix FM and Estonian Star FM declined. This coincided with Star FM's transformation from an all music station, without any DJ's or clear programming to a station very similar to Swedish Rix FM. Programming AC consisting of a large amount (about 35-40\%) of domestic music and Star FM is employing four DJ's and a morning show of three. Star FM is today the third largest station in Estonia, broadcasting (almost) nationwide. ${ }^{1}$ The studio and office in situated in Tallinn and the staff consists of about 30 people (including sales and marketing).

\section{Format radio}

According to David Hendy the vast majority of commercial radio stations adopt a particular format, which he loosely defines as an « overall style and range of programming (Hendy, 2000, p. 98). The production of radio is, as Hendy points out, not the production of content, but the production of style. In the words of radio producer Bob Snyder, quoted from Stephen Barnards 1989 study of music radio in Britain :

We are a radio station, not a collection of programmes [. . . our programming is clinical and disciplined, and the way you do things in radio is actually more important than what you do, it's a how-medium [. . . ] style must come before content [. . .] The typography of the station comes before everything else. (Bob Snyder. Quoted in Barnard 1989, p. 78).

1 Interview, AV/FS 060321 
The format is hence, in Rothenbuler's (1996) definition, the boundaries for what a station will present to the listeners (what kind of music, what kind of contests, what kind of talk et cetera) and also the boundaries for how the station is going to present it. In guidelines, handbooks and courses for people within or heading for the business it is emphasised over and over that the (right) choice of and consequent work in a standardised format is the very key to the listeners heart as well as to future profits (s.f Keith 1987, Norberg 1996). There are a couple of examples of talk formats (news, sports, etc) but out of all formats described and constructed in textbooks and circulating in production the majority are centred on music. Be it a genre (Country, Rock, R ' $n$ ' b, Hip Hop, Disco), a musical period or an era (Adult contemporary, Oldie), a mood (Soft AC), a taste formation (Alternative), or a linguistic and cultural community defined through music (Hispanic, Ethno).

To get to the heart of the logics structuring the idea of format production, it can be fruitful to refer to the etymological grounds for the concept as such. The notion of formation (which the concept format derives from) originates from the Latin word 'formare' which means making something come to life, to give form to or create. From the beginning formation is a military term, used to describe the ways in which armies were positioned on the battlefield. From this origin the word format also have a dimension of intentionality. The radio format is always linked to the intentions of the producer and the conception of the format in production, which separates it from the neighbouring concept of genre. Following the etymological origins of the concept further : the forming of armies was done in order to control the complex events of a battle, a way of disciplining the soldiers and to predict the consequences of the actions and the commands. This idea is remnant in the notion of format radio as well, it is still about competition, conquering competitors and controlling and standardising in order to reach the wanted effect. The standardising is about controlling the listening crowds (audience), the line of production (standardisation) and the program personnel (programming).

The connection between format production and radio operating on a market driven by commercial forces is well established. The history of format production began with Top 40 radio produced in order to reach the teen-audience in the U.S during the 1950s. The turn towards format programming was a direct reaction to the new competition from television on the media market (Fornatale \& Mills, 1980). Since European authorities from the beginning had chosen the public service system 
for organisation of broadcasting it took some time for format radio to hit Europe. After the challenge from off shore pirate radio stations presenting mainly popular music round the clock and competitors like Radio Luxembourg it was a bit paradoxically BBCs Radio One established in 1967, that was the first wide reaching station in Europe trying out the idea of the Top 40-format (Chapman, 1992). During the 1980s and 1990s competitors to the established public service radio-systems could be noticed all over Western Europe, all as a consequence of neo liberal political trends and following deregulations of the broadcasting systems. Music format radio thus became successful as a direct effect of media de-regulation, something that came late in Sweden. The advocates of deregulation in the Swedish debate often stated as an example of the belatedness of Swedish authorities that Sweden together with Albania was the last country in Europe «to set radio free ».

In Eastern Europe the end of communism meant the end of state controlled broadcasting media. In their place, commercial actors, as well as public service broadcasters moulded after the models of Western Europe, began broadcasting. Soon large media companies from Scandinavia and other Western countries started operating in the area (Sparks, 2002). Hence, the idea of formats, and the practice of format production have to be seen in the light of commercialised and de-regulated media markets also in the case of Eastern Europe.

The format is an organising principle for the different segments of time that the producers charge with meaning, making production predictable and standardised. This corresponds to Albert Moran's simile of formats as pies, or rather "the crust" filled with different types of "flavours" in different contexts of production (Moran, 2000). In television these types of formats are also commodities, bought and sold on an international market where producers can buy not only the copyright for the name and core idea of the particular show, but also graphics, music and consulting from the company selling the format (Bolin, 2005a) ${ }^{1}$. Formats however, are slightly different when it comes to radio, as pointed out by David Hendy (2000). Radio formats are not protected by copyright and they are not, as with television program formats, bought

1 The material side of such formats is, except for their status as commodities, manifested through the 'Bible', which is a script that contains all information of how to construct the show in every detail. Typical examples of such formats are reality television shows like Survivor or Big Brother, which have been produced in a substantial number of countries. 
or sold on a market. They are rather free-for-all concepts and ideas, described and maintained through radio textbooks, consulting and the continuous circulation of knowledge within the industry. Further, unlike in television, music format radio does not consist of particular shows or programmes but is best described as a singular continuous flow, where separate programs or larger segments are subordinate to the overall programming. This kind of radio most likely finds its use value as a background to everyday life in and near the home, during leisure time, in the work place or on the way back and forth from work (in the car, via mobile phone, MP3, etc.). Within this single programmes seem insignificant, but for many commercial radio stations and networks of today morning shows are an essential part of the programming process and a key to good ratings.

\section{The production of format radio}

All kinds of format production, in radio as well as in television, bears in common that they have no describable core or essence. Formats are ever changing, structured and structuring modes of production. A format can best be described, as suggested by Albert Moran, « not so much because of what it is, but rather [because of] what it permits or facilitates, [it] has meaning not because of a principle but because of a function or an effect. » (Moran, 1998, p. 18) ${ }^{1}$. Format, in radio production is, as we have seen, a specific logic of the production of a station identity, that is effecting and controlling everything, from the output and stylistics of the station to brand management, sales organisation and marketing. This is the case of Swedish Rix FM and Estonian Star FM where meticulous work is done on setting up and guarding the format through a complex set of programming rules for the combination of segments of music, forms of talk (DJ-talk, guests, news, weather reports, traffic information, phone ins, competitions, etc.), jingles, commercial breaks, etc. Besides this, most successful music stations, irrespective of origin, are centred on the same definitions of genres;

1 In that respect, formats are closely related to the notions of genre, as developed by Tzvetan Todorov and Hans Robert Jauss, where they view genres as abstract entities always existing outside the text itself, and its structure does only subsist in the minds of those imagining it (Jauss, 1968 ; Todorov, 1970). 
the same audio conventions and even the same songs, resting on transnational value systems.

For the concrete work of programming almost all radio stations on the globe use the same kind of production instruments of which a very significant part are computerised systems (often Selector) for scheduling. The music profile is constructed through systematic selection in accordance with predefined categories and ordered frequencies for rotation of songs. A tight music format presupposes a limited stock of songs. In stations not so focused on hits and recent music the variety and stock of songs can be numerous, but in the case of Star FM and Rix FM the circulation often is limited to 300-350 songs (introducing maybe 2-4 new songs per week). Thus the level of repetition is very high and the repetition of music is also one of the core principles of successful programming. The programming rests upon listeners' recognition and familiarity with the product offered. In the many textbooks available on format production advise in this direction is given to programmers. One example : "Successful programming consists of fulfilling listeners expectations, and listeners expectations are based mostly on what the station has done in the past. [...] If your station matches listeners' expectations when they tune in, they feel rewarded, and the behaviour of tuning in your station more often and listening longer is reinforced. » (Norberg $1996:$ 4f).

The concrete programming begins with the production of clocks, the schemata for how to plug individual songs and create the continuous flow of music radio. These clocks can be sorted in to different time frames. By using this system it is possible to create a rational production code, based on repetition and predictability, with large control over the input, or the decoding of the format, connected to the station manager. By following ratings, listener polls on music and special studies on audience behaviour, the station manager can adjust the clocks to better suit the audience's preferences as well as their daily activities and patterns of listening. These clocks make the listener feel at home and confirmed in her expectations and preferences, as these are laid out by the station and experienced by listeners day by day through listening to the station. At the same time the clock makes it possible for the producer to construct a feel of constant newness in the context of overall familiarity (Hendy 2000 : 97). " Yet the overall effect of such infinite variety is often to create a great deal of programming that somehow ends up very similar in its overall feel, whatever the precise individual clock format it employs. » (ibid.) 
The work in order to fulfil these purposes is quite similar at the two stations. Both stations are guided by a PD (programming director), who works closely with the music director (responsible for the actual computerised programming process), and has regular contacts with the market director (responsible for contacts with advertisers etc.) and the technical manager, responsible for the systems for broadcasting and for synchronising the computerized systems for music and ads into a continuous flow. Both the PD of Rix FM (Christer Modig) and at the PD of Star FM (Urmas Kelsar) have had their radio training and education in the U.S, bringing back with them, to their home countries, a set of ideas and values that they have been implementing in their organisations as a part of an ongoing professionalizing of production. The creation of clocks and the important choices of what specific songs that should fill the clocks are negotiated in quite similar ways at the two stations, where 'music meetings' of a formal character are determining the stations short term decisions and where the more strategic and long term choices are seemingly more informally taken and ad hoc where a lot of power lays in the hands of the PD.

Using Hall's model the work with the clocks can be seen as a result of a technical infrastructure, using computerised programming (with Selector). The clocks can also be related to the underlying economic system (producing low cost program feed aimed for a national network). In correspondence with what Hall calls "relations of productions" it is quite obvious that the central power over the encoding and decoding of the format is connected to the station manager and to some degree to the musical manager. The clocks also work as scripts for how the employees regard and perform the idea of the station format. In this way, the clocks together with the musical profile and programming as well as the idea of the model listener, become the framework of knowledge for producers. The framework they negotiate through practices, interpret and decode, and which is expressed through the explicit task of reaching as many ears as possible. For example, the PD of Rix FM, Christer Modig argues that audience ratings are the only way of measuring success. When asked about what quality might mean in the context of commercial radio Modig first finds the question awkward (in the Swedish radio discourse "quality" is a term since long used only 
in relation or public service radio), but then answers : " Quality is the same as a station with many listeners $\gg .^{1}$

For the presenters actually addressing the listener in the act of broadcasting the clocks give a solid framework for how to act in every situation. In addition to this, Rix FM and Star FM have manuscripts with basics for the DJs. These are not word by word manuscripts given to the presenters, the DJs are pretty free in how they lay their words, which in itself becomes a part of the liveness always needed to create what Paddy Scannell calls the authenticity of the broadcast (Scannell, 1996). This technique is also used in the many pre-recorded segments that make up the normal output of Rix FM. Since listeners normally do not pay to listen to commercial radio, the economical logic is to sell ears to advertisers. Listener shares can be measured with different methods, but for each and every station the goal is be to be "top-of-mind" when the inquirers call. This explains why presenters within commercial radio (DJs and others) tend to repeat the name of the station, giving rise to another systematic repetition within the radio texts. According to one of the DJs at Rix FM repetition is at the core in the whole concept of format radio. The number of songs is strictly limited and the importance of naming the stations during broadcast is an essentiality.

MF : You have to mention the name of the station also ?

NN : Of course. [...] Our whole business idea is that people will remember our name if some one asks them for their favourite station. Actually we don't give a damn wheather they actually have listened to us. The main thing is that they think that it is our station that they have been listening to when RUAB (the rating company) calls.

MF : How often do you mention the name of the station ?

$\mathrm{NN}$ : Well, at least two times for each break for talk. You always have to name the station in the beginning and end.

MF : Is that during one hour ?

$\mathrm{NN}$ : No, that's during one break.

1 Interview, CM/MF 060108. 
MF : How long is such a break $?^{1}$

NN : Well, it can be anything from 10 seconds up to 2 minutes. $[\ldots]$ That's the thumb rule. But then you tend to mention the name of the station just by chance. You say things like "check out our home page" or here I am standing in the studio of RIX. The name of the station tends to slip into the language like that.

This is just one example of how the " frameworks of knowledge" is connected to the « relations of production » within the actual practice of the format production process, as the same time as it is a part of the interpretation of what the format is all about.

The notion of the audience is further one of the dominating and all encompassing ideas behind format radio. To compile demographic data and to shape a model listener is the very beginning of formatting, as expressed by PD of Estonian Star FM Allan Vinogradov : "The single most important thing in doing music radio is to know who is your $\mathrm{P} 1$ listener" 2 . The P1 is the person having your station as a favourite; this listener is both a generalisation of the existing core listeners and an ideal for the station to strive towards. Every move in programming is made with the listener in mind. Songs are tested in continuous weekly call-outs and thereafter categorised and placed in rotation or - if rejected by test respondents - ejected from schedules and playlists. Similar tests are - even though not as often - conducted on air-personnel and activities such as contests or other segments like news or weather reports. Moreover, the listener exists as a manifest fantasy, in the Studio of Star FM in Tallinn, one can read the following on a poster on the wall :

She is 33 years old

She has 2 children

She is living in the suburbs

She is married

She is working in an office

She is stylish, but not so trendy

She sports twice a week

She is shopping at large supermarkets

She has a 5 year old leasing-car (or 3-5 year old Toyota or Wolksvagen).

1 Interview, NN/MF 050525.

2 Interview, AV/FS 060321 
She Reads female-journal ANNE and Estonian Daily Newspaper

She is the mental image of the P1 and the one listener the DJs are supposed to talk to. She is the one listener the music directors are supposed to programme the music for and the one in mind for every step taken also within marketing and sales. In the production of Swedish Rix FM the stations P1 is named Lena, and in addition to a similar note on the studio wall, the DJs are also taught to constantly ask themselves this question : «What is Lena up to right now? ». In the formal Air-Personality Guide, made for the DJs, one can read : « Use one-to-one communication. Intersect with the listeners daily life ». The 'She' of Star FM or Rix FMs 'Lena' of course does not exist. It doesn't matter though, the fantasy of this person materialise the station's model listener and makes the producers act in specific ways. Therefore you can say that she is as real as - or actually more real than - every other member of the audience. All in all this highlights the audience's status in commercial radio production. The audience is mainly an immaterial or symbolic artefact produced as a vehicle for a rational and unified production process, and as a commodity to be sold on a market, the marketplace of ears.

These various logics - repetition in radio text, standardisations of programming and fantasies of the audience - are the basis for the idea of the format, as it subsists in the minds and actions of the producers of commercial music radio and as it materialises through negotiations within the line of production.

\section{Closing discussion first steps towards an analytic model}

In this article we have argued for the relevance of studies of commercial music radio, especially empirical studies of format production. We mean that this is both a way to gain new knowledge in a somewhat under-researched area and a fruitful point of departure for more theoretical concerns about the relation between local and transnational cultural production. Format production in radio differs from format production in the field of television. The context of radio format emphasises the level of channel rather than the individual programme. Thus the main concerns for formatted radio stations are about the 
channel as a brand and its standardised and repetitive production practices, and the strategic handling of its (pre)defined audience.

As a way to comprehend the process of decoding or interpretation of formats we want to reactivate Stuart Hall's encoding-decoding model by applying it to the study of radio production, i.e. seeing encoding as a form of decoding. By empirical examples taken from the Swedish network Rix FM and its somewhat equivalent part within the Estonian radio market, Star FM (both working within the AC-format), we point to certain logics and steps within the production of the station format. From this it seems possible to chisel out dimensions, steps and stages that in a more general way can help us understand the logics of an ongoing decoding of radio formats - over time and within different radio station contexts, and in each of which a continuous negotiating over radio's function, role and effect could be detected and analysed.

One fundamental dimension is the strategic work, with initial decisions taken on which format to launch, usually done after analysing the present radio market, guiding the set up of rules of the programming process. This choice of format leads to standards and rules for the programming of music and other content, which in turn is a screen for the actual choices and combinations of songs made through computerised music programming. This profile in turn is the basis for communication taking place through DJ talk, jingles and other factors of enunciation in the actual broadcast (mode of address, routines for addressing the audience, forms and frequencies for station reminders and branding). A final dimension is evaluative, i.e. how the audience is rated and constructed.

From this it seems possible to develop a model for studies of wider empirical materials, to make interpretations of the relation between local and trans-national where also nationally specific radio history and the developments within different countries can be taken into account. The discussions of different phases in the ongoing (re)production of formats should also be linked to different forms of intentionality, in connection with the actual people involved in the production of the format. For example : quite a few of the leaders in the early phase of Swedish commercial radio in the early 1990s dreamed of a truly local radio and had their background in pirate radio or community radio. This carried with it some historically specific views on the criteria for the programming of music into the early phase of Swedish commercial radio. Later on, some of these rather idealistic standpoints and actors collided with, and were replaced by, business oriented views and persons. This had a 
notable effect on the decoding of, for example, music programming, which over time has lead to a much more rationalised market characterised by more hard formatted commercial music radio and networks with both national and trans-national ambitions.

\section{References}

\section{Books and Articles}

Andersson, Benedict (1991) Imagined Communities : reflections on the origins and spread of nationalism, London: Verso.

Barnard, Stephen (1989) On the Radio. Music Radio in Britain, Stratford : Open University Press.

Bolin, Göran (2005a), En form av television. Globaliseringen av nationell tevekultur, (A Form of Television. The Globalisation of a National Television Culture) i MedieKultur, nr 39, 2005 pp. 38-49.

Bolin, Göran (2005b), Notes From Inside the Factory. The Production and Consumption of Signs and Sign Value in Media Industries, in Social Semiotics, vol. 15(3), pp. 289306.

Berland, Jody, Radio Space and Industrial Time. The Case of Radio Formats, in Bennett,

Tony (ed.) (1993) Rock and Popular Music. Politics, Policies, Institutions, London \& New York : Routledge.

Chapman, Robert (1992) : Selling the sixties. The pirates and pop music radio, London \& New York : Routledge.

Coyer, Kate (2005), Where the 'Hyper Local' and 'Hyper Global' Meet : Case Study of Indymedia Radio, Westminster Papers in Communication and Culture, Vol. 2(1) :3050, London : University of Westminster.

Curran, James and Park, Myung-Jin (2000) De-Westernizing Media Studies, London \& New York : Routledge.

Durham Peters, John(1999): Speaking into the air. A history of the idea of communication, Chicago and London: The University of Chicago press.

Fornatale, Peter \& Mills, Joshua E. (1980) Radio in the Television Age, New York: The Overlook Press.

Hall, Stuart, Encoding/decoding, i Hall (1980) (red.) : Culture, Media, Language. Working Papers In Cultural Studies 1972-79. London: Hutchinssons in association with the Centre for Contemporary Cultural Studies, University of Birmingham.

Hendy, David (2000) Radio in the Global Age, Cambridge : Polity Press. 
Jauss, Hans Robert, Theorie der Gattungen und Literatur des Mittlealters, (Theory of the genres and literature of the Middle-Ages), in Haettner Aurelius, Eva \& Götselius Tomas (1997) Genreteori, Lund : Studentlitteratur.

Jensen, Pia Majbritt, Formatversionering. Et overblik, (Format programming. An overview), in MedieKultur, nr 39, pp. 38-49, 2005.

Moran, Albert (1998) Copycat television : globalisation, program formats and cultural identity, Luton : University of Luton Press.

Moran, Albert \& Keane Michael (eds.) (2003) Television across Asia : television industries, programme formats and globalization, London : Routledge.

Norberg, Eric G. (1996) Radio Programming. Tactics and Strategy, Boston : Focal Press.

Rothenbuler, E, Commercial Radio as Communication, in Journal of Communication, 46 (1), 1996, pp. 125-43.

Scanell, Paddy (1996) Radio, Television and Modern Life. A phenomenological approach, Oxford: Blackwell.

Sparks, Colin (2000), Media Theory After the Fall of European Communism. Why the old models from East and West won't do any more, in Curran, James\&Park, MyungJin (2000) De-Westernizing Media Studies, London \& New York : Routledge.

Thompson, John B (1995) Media and Modernity. A social theory of the media, Stanford CA : Stanford University Press.

Todorov, Tzvetan, Les Genrés Littéraires, (The Literary Genres) in HaettnerAurelius, Eva \& Götselius Tomas (1997) Genreteori, Lund : Studentlitteratur.

Williams, Raymond (1975) Television. Technology and Cultural Form, New York : Schocken Books.

Ytreberg, Espen (1999) Allmenkringkastningens autoritet. Endringer I NRK Fjernsynets tekstproduksjon 1987-1994. The Authority of Public Service. Changes in the Text Production of NRK Television 1987-1994), Oslo : Institutt for medier og kommunikasjon.

Ytreberg, Espen (2000), Notes on Text Production as a Field of Inquiry in Media Studies, in Ulla Carlsson (ed) Nordicom Review, vol $21: 2$.

\section{Other sources}

Interview with DJ at RIX FM, 050525

Interview with Christer Modig, station manager Rix FM, Sweden, 060108.

Interview with Urmas Kelsar, former PD Star FM Estonia 060322

Interview with Allan Vinogradov, PD Star FM Estonia 060321

Air-Personality Guide, Rix FM 
